\title{
Integrated GDP-Productivity Accounts
}

By Michael J. Harper, Brent R. Moulton, Steven Rosenthal, and David B. Wasshausen

December 2008

\section{Appendix: NIPA - MFP Reconciliation}

Appendix Table A.1, "Relation of NIPA GDP to BLS Private Sector Current Dollar Output,” presents BEA and BLS estimates beginning with 1998. ${ }^{1}$ Although BLS presents their major sector MFP estimates for private business and private nonfarm business only, it is important to note that these estimates are derived at the industry level and then aggregated to the major sector level. These nominal MFP estimates are primarily derived using BEA's annual industry accounts (AIA) gross value added (and components thereof) by industry estimates so that there is essentially a 2-step reconciliation process: First reconcile NIPA estimates to the AIAs, second reconcile AIAs to MFP. Fortunately there are few differences between BEA's NIPA and AIA estimates, particularly with respect to components of labor and capital income, making it possible to circumvent this first step with regard to producing a meaningful NIPAMFP reconciliation table.

The first part of the table shows the derivation of BLS private business sector output from NIPA gross domestic product (GDP). Starting with GDP on line 1, we remove GDP associated with households, nonprofit institutions serving households (NPISH), and general government, resulting in business sector gross value added (GVA). These estimates are all published in NIPA Table 1.3.5. Next, we subtract GVA for government enterprises, resulting in private business sector GVA (line 10). GVA for government enterprises is taken from the AIAs, as it is not published as part of the NIPAs. BLS private business sector GVA (line 12) is equal to NIPA

\footnotetext{
${ }^{1}$ Estimates presented are as of May 2008.
} 
private business sector GVA (line 10) less statistical differences primarily due to timing of data. Next, BLS private business sector output can be broken down into four components:

1. BLS labor compensation;

2. BLS capital income;

3. BLS adjustment to property income for finance and insurance industries;

4. BLS taxes on production and imports (TOPI), less portion assigned to capital income, less subsidies.

BLS labor compensation (line 13) consists of BLS employee compensation (line 14) plus a BLS adjustment that reassigns a portion of NIPA proprietors' income to labor income (line 19). The idea is that a portion of proprietors' income represents wages of the proprietor and as such should be classified as labor compensation for MFP purposes. The remaining portion of proprietors' income is treated as capital income. BLS and NIPA employee compensation differ by the amount shown on line 16, labeled "other." This line is further broken down into two components: "Household compensation" (line 17) and "Portion of NIPA NPISH compensation assigned to capital income.” BLS employee compensation for private business equals all private industry compensation less compensation for NPISH. Compensation for households should also be removed, but presently is not. BLS plans to address this in their next release. In addition, the BLS estimate for NPISH compensation is less than the corresponding NIPA estimate and therefore BLS private business compensation is higher.

BLS capital income (line 20) consists primarily of NIPA gross operating surplus (lines 21-26) plus a portion of TOPI assigned to capital income (line 28). The NIPA statistical discrepancy (line 27), which vacillates between positive and negative, is also assigned to capital income. All but one of the NIPA line items is published or can be derived from published data: 
Business current transfer payments for private business sector. This item is calculated as total NIPA business current transfer payments (published) less business current transfer payments for households (unpublished). The portion of TOPI assigned to capital income consists of business property taxes and business motor vehicle licensing fees. Remaining TOPI are considered to be neither labor nor capital income and are accounted for separately in the reconciliation table (line 36). Several items are subtracted and offset entries included above under labor compensation: “BLS adjustment for proprietors’ income” (line 29), "Household compensation” (line 30), and "Portion of NIPA NPISH compensation assigned to capital income" (line 31). An adjustment is also made to account for differences in property income for finance and insurance (line 32). BLS imposes an external rate of return on finance and insurance industries without forcing to NIPA income. BLS inadvertently subtracts TOPI less subsidies for households and institutions (line 33). TOPI less subsidies for households and institutions should not be subtracted from the items listed above and BLS plans to address this in their next release. Finally, "other” (line 34) is a residual and reflects several things. First, small differences in any year can be attributed to rounding as BLS builds their estimates up from industry detail whereas the NIPA may or may not. Second, for years 1998 to 2000 GVA for NPISH reported in NIPA Table 1.3.5 incorrectly excludes residential consumption of fixed capital (CFC) for NIPISH. As a result, the BLS estimate for private business sector capital income includes residential CFC for NPISH. ${ }^{2}$ Lastly, for 2005 and 2006, estimates primarily reflect the statistical discrepancy shown in line 11.

It is necessary to add back in the adjustment to property income for finance and insurance (line 35) in order to come back to private business sector GVA. It is also necessary to add the remaining portion of TOPI less subsidies that was not assigned to capital income. Note, TOPI

\footnotetext{
${ }^{2}$ BLS controls their estimate of GVA for households and institutions to what is published in NIPA Table 1.3.5. This control total is assigned to either labor or capital and then used to remove households and institutions from private industry labor and capital income estimates. BEA plans to address this in its upcoming comprehensive revision.
} 
less subsidies (line 37) includes households and institutions and is taken directly from the AIAs. Including TOPI less subsidies for households and institutions is necessary here in order to offset the inadvertent subtraction of it in line 33. When TOPI less subsidies for households and institutions is no longer subtracted in the derivation of capital income, it will not be included under the part of TOPI less subsidies that was not assigned to capital income. 
Table A.1--Relation of NIPA GDP to BLS Private Sector Current Dollar Output [Billions of Dollars]

\begin{tabular}{|c|c|c|c|c|c|c|c|c|c|c|}
\hline & & 1998 & 1999 & 2000 & 2001 & 2002 & 2003 & 2004 & 2005 & 2006 \\
\hline Gross Domestic Product & 1 & $8,747.0$ & $9,268.4$ & $9,817.0$ & $10,128.0$ & $10,469.6$ & $10,960.8$ & $11,685.9$ & $12,433.9$ & $13,194.7$ \\
\hline Less: Households and institutions gross value added & 2 & 949.7 & $1,012.3$ & $1,080.7$ & $1,160.4$ & $1,227.3$ & $1,269.2$ & $1,350.0$ & $1,404.7$ & $1,500.3$ \\
\hline Housholds & 3 & 538 & 576.4 & 615.6 & 662 & 687.7 & 699.9 & 744.9 & 773.3 & 834.2 \\
\hline Nonprofit institutions serving households & 4 & 411.7 & 435.9 & 465.1 & 498.4 & 539.6 & 569.3 & 605.1 & 631.4 & 666.1 \\
\hline General government gross value added & 5 & 970.3 & $1,012.7$ & $1,069.6$ & $1,126.4$ & $1,201.8$ & $1,280.1$ & $1,348.4$ & $1,425.9$ & $1,501.5$ \\
\hline Equals: Business sector gross value added & 6 & $6,827.0$ & $7,243.4$ & $7,666.7$ & $7,841.2$ & $8,040.5$ & $8,411.5$ & $8,987.5$ & $9,603.3$ & $10,192.9$ \\
\hline Less: Government enterprises & 7 & 124.2 & 128.5 & 133.1 & 131.9 & 136.6 & 138.3 & 143.2 & 142.8 & 147.8 \\
\hline Federal & 8 & 59.9 & 61.0 & 63.4 & 60.0 & 64.5 & 64.7 & 66.8 & 63.7 & 67.8 \\
\hline State and local & 9 & 64.4 & 67.6 & 69.7 & 71.9 & 72.2 & 73.7 & 76.4 & 79.1 & 80.0 \\
\hline Equals: Private business sector gross value added & 10 & $6,702.8$ & $7,114.9$ & 7,533.6 & $7,709.3$ & $7,903.9$ & $8,273.2$ & $8,844.3$ & $9,460.5$ & $10,045.1$ \\
\hline Less: Statistical discrepancy /1/ & 11 & -0.1 & 0.0 & 0.0 & 0.0 & 0.0 & 0.0 & 0.0 & 3.8 & -10.7 \\
\hline Equals: BLS Private business sector current dollar output & 12 & $6,702.8$ & $7,114.9$ & 7,533.6 & $7,709.3$ & 7,903.9 & $8,273.2$ & $8,844.3$ & $9,456.7$ & $10,055.7$ \\
\hline BLS Labor compensation & 13 & $4,165.6$ & $4,463.4$ & $4,809.4$ & 4,911.6 & $4,970.4$ & $5,154.3$ & $5,440.4$ & $5,762.5$ & $6,120.0$ \\
\hline BLS employee compensation & 14 & $3,788.5$ & $4,070.5$ & $4,414.7$ & $4,500.4$ & $4,547.3$ & $4,688.6$ & $4,924.6$ & $5,211.9$ & $5,538.8$ \\
\hline NIPA employee compensation & 15 & 3733.4 & 4012.8 & 4355 & 4438.9 & 4482.1 & 4615.3 & 4846.6 & 5132.6 & 5456.4 \\
\hline Other & 16 & 55.1 & 57.7 & 59.7 & 61.5 & 65.2 & 73.3 & 78.0 & 79.2 & 82.4 \\
\hline \multicolumn{11}{|l|}{ Of which: } \\
\hline $\begin{array}{l}\text { Household compensation } / 2 / \\
\text { Portion of NIPA NPISH compensation assigned to capital income }\end{array}$ & 17 & 14.0 & 12.7 & 13.6 & 12.8 & 12.6 & 13.9 & 14.9 & 14.9 & 15.6 \\
\hline \multirow[b]{2}{*}{ BLS adjustment for proprietors' income /4/ } & 18 & 41.1 & 45.0 & 46.1 & 48.7 & 52.6 & 59.4 & 63.1 & 64.3 & 66.8 \\
\hline & 19 & 377.1 & 392.9 & 394.7 & 411.2 & 423.0 & 465.7 & 515.7 & 550.6 & 581.1 \\
\hline BLS Capital income & 20 & $1,909.8$ & $2,008.0$ & $2,050.3$ & $2,113.5$ & $2,180.3$ & $2,328.9$ & $2,567.9$ & $2,809.0$ & $2,964.6$ \\
\hline NIPA Corporate profits with IVA and CCAdj & 21 & 698.7 & 729.8 & 672.2 & 597.6 & 730.5 & 827.7 & $1,037.8$ & $1,154.6$ & $1,296.4$ \\
\hline NIPA Proprietors' income with IVA and CCAdj & 22 & 627.8 & 678.3 & 728.4 & 771.9 & 768.4 & 811.3 & 911.6 & 969.9 & $1,006.7$ \\
\hline NIPA Net interest and miscellaneous payments & 23 & 296.0 & 292.3 & 350.7 & 353.2 & 294.1 & 276.9 & 229.2 & 279.5 & 310.0 \\
\hline NIPA Rental income of persons & 24 & 58.1 & 58.7 & 59.6 & 65.7 & 57.3 & 52.0 & 49.2 & 42.7 & 48.2 \\
\hline NIPA Business current transfer payments & 25 & 63.2 & 66.1 & 86.6 & 95.4 & 82.4 & 79.6 & 82.3 & 77.5 & 80.1 \\
\hline NIPA CFC & 26 & 718.3 & 769.8 & 836.1 & 903.7 & 893.6 & 916.6 & 970.2 & $1,060.4$ & $1,081.4$ \\
\hline NIPA Statistical discrepancy & 27 & -14.6 & -35.7 & -127.2 & -89.6 & -21.0 & 48.8 & 19.1 & 5.4 & -18.1 \\
\hline Portion of TOPI assigned to capital income /5/ & 28 & 104.9 & 110.2 & 115.5 & 121.3 & 130.3 & 138.1 & 146.7 & 155.2 & 164.7 \\
\hline
\end{tabular}


Table A.1 (continued)--Relation of NIPA GDP to BLS Private Sector Current Dollar Output [Billions of Dollars]

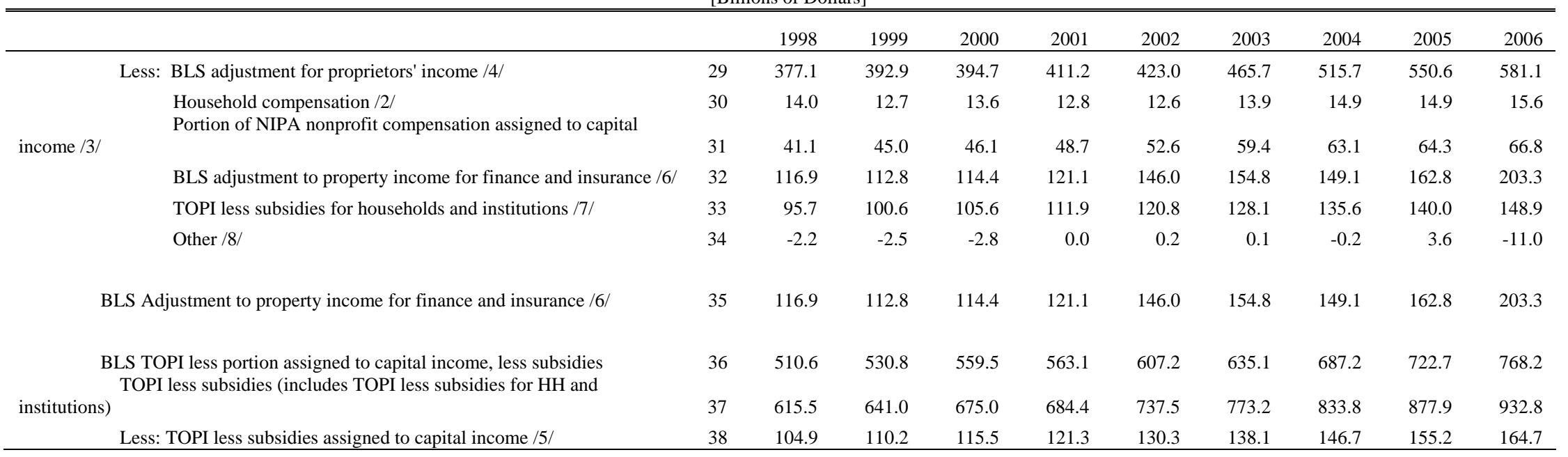

/1/ For 2005 and 2006, BLS estimates reflect data from the Census Bureau's accelerated November 2007 release of the Annual Survey of Manufactures (ASM) whereas the NIPAs do not.

/2/ BLS employee compensation for private business equals all private industry compensation less compensation for NPISH. Compensation for households should also be removed but presently is not. BLS plans to address this in their next release.

/3/ The BLS estimate for NPISH compensation is less than the corresponding NIPA estimate and therefore BLS private business compensation is higher.

/4/ BLS assigns a portion of NIPA proprietors' income to labor income.

15/ BLS assigns a portion of NIPA TOPI, e.g., business property taxes and business motor vehicle licensing fees, to capital income.

/6/ BLS imposes an external rate of return on finance and insurance industries without forcing to NIPA income.

/7/ BLS inadvertently subtracts TOPI less subsidies for households and institutions. These should not be subtracted in their computation of private business capital income. BLS plans to address this in their next release.

/8/ For 2005 and 2006, primarily reflects statistical discrepancy shown in line 11. For 1998, 1999, and 2000, primarily reflects residential CFC for NPISH, which is inadvertently included in BLS capital income in these years.

NOTE. Figures reflect published estimates as of May 2008. 